\title{
A cidade à noite: tensões e sociabilidade no espaço público pelotense (Pelotas-RS, 1930-1939)
}

The city at night: tensions and sociability in the public space of Pelotas (Pelotas-RS, 1930-1939)

\author{
Thaís de Freitas Carvalho*
}

\begin{abstract}
Resumo
O presente estudo discute a noite pelotense de 1930 a 1939, com ênfase nas sociabilidades noturnas ligadas à cultura popular desse período. A escolha da década de 1930 do século passado refere-se à conjuntura de urbanização e modernização da cidade de Pelotas, percebida na análise do desenvolvimento do espaço urbano, eletrificação e dinamização das atividades culturais. Torna-se evidente a relação da cidade e seus habitantes com concepções e noções de comportamento ligadas aos ideais de modernidade e civilidade, os quais carregavam elementos de normatização que serviam ao surgimento de um capitalismo voltado ao consumo. O confronto entre estes novos padrões de convivência social e os velhos valores herdados de um modo de vida rural é contemplado neste trabalho por meio da análise das sociabilidades noturnas presentes nesse universo popular. O tempo noturno, escolhido por privilegiar o domínio dos trabalhadores sobre seu tempo, revela esses e outros traços de uma cultura popular que se mostra efervescente e singular. Partindo das declarações e depoimentos contidos nos inquéritos policiais e processos criminais do período, torna-se possível visualizar a vitalidade de uma noite popular que transitou pelas ruas e recheou o espaço urbano com seus encontros, seus conflitos e seus amores.
\end{abstract}

Palavras-chave: Noite; Sociabilidade; Espaço público; Honra; Cultura popular.

\begin{abstract}
The following study discusses Pelotas' night between 1930 and 1939, with emphasis on night-time sociabilities linked to popular culture in the period. The choice of the 1930s relates to the context of urbanization and modernization of the city, perceived in the analysis of urban development, electrification and promotion of cultural activities. It is evident that the relationship of the city and its inhabitants with conceptions and notions of behavior linked to the ideals of modernity and civility, which carried elements of regulation that served the emergence of a capitalism oriented to consumer relations. The confrontation between these new patterns of social interaction and those old values inherited of a rural way-of-life is considered in this work through the analysis of the night-time sociabilities present in this popular universe. The night-time, chosen for favoring the dominance of employees on their free time, reveals these and other traces of a popular culture that presents itself effervescent and singular. Starting from the statements and testimony contained in police investigations and criminal prosecutions of the period, it becomes possible to visualize the vitality of a popular night that wandered through the streets and filled urban space with their meetings, their conflicts and their loves.
\end{abstract}

Keywords: Night; Sociability; Public Space; Honor; Popular culture.

\footnotetext{
* Doutoranda em História pela Pontifícia Universidade Católica do Rio Grande do Sul (PUC-RS). Mestre em História pela Universidade Federal de Pelotas (UFPel). Bolsista CNPq.
}

Recebido em outubro de 2016 | Aprovado em maio de 2017. 
Enquanto a cidade dorme, em certas ruas, nos bares, nos cabarés, nos salões de bilhar, em salas pouco iluminadas e enfumaçadas, nos salões de dança e strip-tease, as tensões urbanas emergem, vivenciadas de formas fragmentadas e diversificadas por seus frequentadores, fazendo da cidade lugar para se trabalhar, se divertir, viver aventuras e desventuras da noite. (SIMMEL, 2006, p. 81).

A década de 1930 presenciou densas transformações no cotidiano popular: o rádio, o cinema, os bondes elétricos, tudo apontava na direção do futuro, do moderno e engenhoso. A lógica de mercado invadia as vidas, as casas e a mentalidade de pessoas ainda apegadas a um modo de vida mais árcade, no qual as relações seriam mais orgânicas. Nessa nova ordem social, que já vinha se infiltrando desde os anos anteriores (década de 1920), cada atitude requeria um cerimonioso cuidado, pois as noções de civilidade eram propagadas e fiscalizadas, no intuito de moldar uma nação patriota e consciente de seu papel em prol do progresso.

Faz-se necessária, também, a compreensão de um contexto cultural como o pelotense, permeado de interações comerciais, étnicas e culturais, por meio dos portos, viagens de trem, além de apresentar uma bagagem de influências platinas, herdadas de um tempo em que o território do atual Estado do Rio Grande do Sul era disputado entre espanhóis e portugueses. ${ }^{1}$ Nesse sentido, algumas características socioeconômicas da região agregaram componentes culturais à população e por isso devem ser de entendimento do leitor. Por exemplo, a região Sul do Estado carrega a tradição do manejo de um grande número de cabeças de gado, inicialmente espalhadas na região, livremente e que constituiu a principal forma de exploração econômica da área. De fato, as características dessa região são as responsáveis pelo imaginário clássico a respeito da

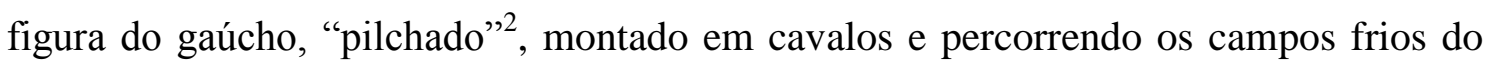
Sul nos trabalhos rurais. Já a metade Norte do Rio Grande do Sul recebeu, nos períodos republicanos, mais incentivos para a diversificação da produção, sendo colonizada massivamente por imigrantes europeus. Quando a economia baseada na pecuária sofreu crises devido à necessidade de modernizações e condições de equilibrar a concorrência platina, o Sul do Estado se viu, pela primeira vez, ultrapassado economicamente,

\footnotetext{
${ }^{1}$ Sobre essas heranças, recomendo o livro de Mario Osorio Magalhães (2002), História do Rio Grande do Sul (1626-1930).

${ }^{2}$ Expressão referente à vestimenta típica dos homens deste cenário social sul-rio-grandense de trabalho no campo (apropriada pela cultura regional), composta por bombachas (espécie de calça larga), lenço no pescoço, pala (manta artesanal de lã), poncho (casaco de lã sem mangas, cobrindo o corpo desde o pescoço até os joelhos) e botas de montaria.
} 
relatando considerável empobrecimento em relação ao crescimento das outras regiões (VIEIRA, 1997, p. 83).

$\mathrm{Na}$ verdade, sobre essas questões das disparidades regionais, pode-se observar que, no censo de 1920, havia um equilíbrio da distribuição dos habitantes do Estado entre as duas metades. Vinte anos depois, a proporção passou para $41 \%$ no sul e $59 \%$ ao norte e, ainda, se se adiciona Porto Alegre à metade norte, a proporção chega a $37 \%$ no sul, contra $63 \%$ no norte. Contudo, é válido salientar que o sul se impunha na proporção de indivíduos com curso superior, o que certamente se deve aos resquícios da riqueza de elites estancieiras e charqueadoras, que enviavam seus filhos para estudar nas melhores universidades do país e do exterior (GERTZ, 2005). Mesmo com a economia da região fragilizada, é significativo que, em 1940, Pelotas figurasse como o $4^{\circ}$ município mais populoso do Estado - 104.553 habitantes - e, embora abaixo de Porto Alegre, Palmeira das Missões e Erechim, estava entre os restritos municípios gaúchos com mais de 100 mil habitantes (SOARES, 2007).

Portanto, o período em destaque, embora constitua um momento de crise, foi de inúmeras mudanças e inovações. Novidades estruturais, tecnológicas, industriais traziam ao Sul do país, um mundo novo, cheio de oportunidades e modernidade. A região de Pelotas começou a perceber um surto de fábricas dos mais diversos utensílios domésticos e tem-se, na década de 1930, o início do que se pode chamar de uma transição de um capitalismo arcaico e tradicional para uma cultura de consumo. É evidente que tais mudanças não refletiram em uma transformação do caráter agropastoril do Estado como um todo, tampouco fizeram da região Sul um polo industrial. Ainda assim, sem dúvida transformou o modo de vida de diversos setores sociais em Pelotas, trazendo atividades, desejos, rotinas e trajetos que revelavam uma aceleração da vida urbana (RÜDIGER, 2007).

A própria conjuntura política brasileira havia sofrido, com a chegada da década de 1930, consideráveis transformações, a partir do momento em que rompia com uma república de revezamentos entre os principais Estados do centro do país - São Paulo e Minas Gerais - em que o governo de Getúlio Vargas inaugurava uma nova forma de administração, mais voltada para a integração de todos os Estados, em uma política nacional centralizada.

Reflexos dessas transformações são algumas medidas que marcaram a primeira metade da década de 1930, por exemplo, os investimentos na educação. A Constituição de 1934 traria uma série de benefícios também às conquistas da legislação trabalhista, 
como o salário mínimo, o descanso semanal, as férias remuneradas e a regulamentação do trabalho das mulheres e dos menores. Em 1935, foi criada a Secretaria de Estado dos Negócios da Educação e da Saúde Pública, evidenciando uma preocupação estrutural do governo em garantir as mínimas condições de salubridade à população, que, na maior parte das cidades do interior, convivia com instalações precárias ou inexistentes de saneamento (PETERSEN; PEDROSO, 2007). Esse primeiro período de governo varguista foi marcado por investimentos estruturais, com destaque para o fornecimento de energia e a regulação dos órgãos que administravam os recursos hídricos (LONER; GILL; MAGALHÃES, 2010, p. 142).

O surgimento da energia elétrica parece ter representado uma revolução nos hábitos de divertimentos da cidade, principalmente os noturnos. Geruza Esteves Borges (2008), que investigou o processo de instalação da rede elétrica em Pelotas, afirma que

Em Pelotas, a iluminação pública passou por várias fases. Começou com a utilização de lampiões, ainda na primeira metade do século XIX, passando pelo sistema de iluminação a gás encanado, que teve início no ano de 1875. E, por fim, chegou ao uso da eletricidade no primeiro quartel do século XX. (BORGES, 2008, p. 20).

O período aqui estudado (década de 1930), portanto, já presenciava a eletricidade no funcionamento dos bondes e iluminação pública, desde 1915, quando começou a eletrificação na cidade, porém, conviveu com a iluminação a gás durante bastante tempo, até princípios da década de 1940. A autora citada destaca as propagandas veiculadas nos jornais da época, incentivando a população a trocar a iluminação a gás das residências pela energia elétrica, indicada como mais limpa e segura. Na verdade, o século XX marca o início de uma era de rápidas mudanças tecnológicas e avanços da ciência, o que contribui para a ideia de impactos subsequentes na vida das populações, com significativas transformações em seu cotidiano. Ela esclarece que "A noção de tempo e espaço se modificou, e novas práticas e 'valores' passaram a fazer parte de vários setores da cultura" (BORGES, 2008, p. 17).

Passava-se de uma era romântica para a era do capitalismo de consumo, na qual diversas atividades, antes inexistentes pela ausência de energia, agora passavam a fazer parte da noite e rechear o passeio público de ofertas comerciais. Além da maior adesão às sociabilidades noturnas, sabe-se que atividades como a ida ao cinema também tiveram ampla adesão em Pelotas, após a eletrificação, sendo as sessões noturnas as mais disputadas. Pesquisadores como Loner, Gill e Magalhães (2010) afirmam: 
No início dos anos 30, a cidade dispunha de mais de uma dezena de salas exibidoras. Com o advento do cinema sonoro [...] proliferaram as empresas exibidoras e as salas se espalharam do centro para a periferia urbana, instituindo os cinemas de bairro. (LONER; GILL; MAGALHÃES, 2010, p. $63)$.

Destacam-se alguns impactos residenciais importantes dessa modernidade, como a utilização de aparelhos domésticos, por exemplo, a geladeira e o gramofone, os quais sabe-se hoje, foram instrumentos - ainda que cada um à sua maneira - de novas condições de vida e acesso à cultura. O próprio funcionamento da "Rádio Pelotense" (1928) teve suas primeiras transmissões oficiais "das 21 às 23 horas, nas noites de quinta-feira e domingo", o que reforça a ideia de uma noite que se adensava (LONER; GILL; MAGALHÃES, 2010, p. 214). O vínculo do aparecimento da energia elétrica com uma atmosfera de apropriação de novos hábitos que estendiam o tempo da cultura popular, não deixa de fazer parte dos sintomas de uma aspiração à modernidade, sentida em outras partes do país e ligada a novos valores culturais expressivos de uma urbanidade civilizada.

Revelaram-se os reflexos da dinâmica, envolvendo novas relações com o espaço público, a migração de um contingente considerável da população das zonas rurais para o âmbito urbano, as novas atividades culturais propiciadas por inovações tecnológicas e a situação social dos setores, aqui contemplados, enquanto classes populares, seu cotidiano e costumes. É inegável que tal contexto propiciasse uma série de enfrentamentos, pois foram muitas mudanças no poder político, nas formas de administração, vigilância, relações étnicas e expressões culturais.

Trabalhando a partir da análise das ocorrências noturnas presentes nos inquéritos policiais, anexados aos processos criminais da Comarca de Pelotas, chegou-se a um universo de mais de 100 processos de ocorrências noturnas, desde incêndios, arrombamentos, atropelamentos e defloramentos, a um circuito de atividades culturais envolvendo bailes, bares, cafés e "pensões alegres". Pelotas abarcava uma vida noturna recheada de interações e conflitos, nos quais hoje se encontram, refletidos nas folhas dos processos criminais, todos esses estranhamentos e associações mencionados, que fizeram desse período da história da cidade um símbolo de sua arraigada contradição: provinciana versus cosmopolita.

Pretende-se mostrar, aqui, que mesmo na década de 1930, e em uma cidade do interior do Rio Grande do Sul, em que valores morais de uma herança pastoril ainda confrontavam-se com a lógica comportamental da modernidade, vê-se uma vida noturna 
que buscava se desenrolar segundo a nova ordem de mercado, em que os valores já tinham sua base no bom funcionamento e desenvolvimento do sistema capitalista.

$\mathrm{Na}$ verdade, focalizar, neste estudo, a noite popular, pública e de fácil acesso, se fez com o intuito de perceber o funcionamento das noites democráticas em Pelotas, entender como a gente simples da década de 1930, trabalhadores e transeuntes que moviam o cotidiano da cidade, divertiam-se nas poucas horas em que descansavam, ainda acordados, depois de um dia de trabalho. Buscou-se a sociabilidade de espaços e situações em que, a princípio, qualquer indivíduo tinha acesso e, mais além, encontros noturnos, nos quais questões primordiais em outras relações e tempos cotidianos, como o trabalho, não seriam prioridade.

\section{Notívagos e sociabilidade no espaço público}

Não por acaso, percebeu-se, no decorrer da pesquisa, a predominância de uma rede de sociabilidade masculina, nas noites estudadas. Apesar de algumas mulheres serem vistas na noite, quase sempre, essas ocorrências eram ligadas a comportamentos e/ou atividades condenáveis, em um contexto, no qual o simples ato de uma mulher andar na rua desacompanhada servia como atestado de má conduta e moral duvidosa. Sobre os papeis do homem e da mulher ligados à honra da família, é pertinente salientar que

[...] os papeis femininos estavam expressos de forma negativa, para uma adequada moral sexual, e consequente manutenção da honra familiar, [as mulheres] deveriam guardar a virgindade, a fidelidade e a castidade. Ou seja, para ter honra a mulher não deve fazer/ter condutas inapropriadas. Estes eram os eixos centrais da honra feminina e o não cumprimento de qualquer deles não somente desonrariam as mulheres envolvidas como todo o grupo familiar e, especialmente, os homens aos quais elas estavam ligadas. Já os homens têm um papel positivo, devem demonstrar suas virtudes masculinas desempenhando práticas relacionadas com a lealdade, a valentia, a coragem, a capacidade de controlar as mulheres sob sua responsabilidade. (REMEDI, 2011, p. 11).

Contudo, deve-se lembrar que a conduta das mulheres pobres no cotidiano do início do século estava inegavelmente relacionada ao fator socioeconômico e isto fica bastante evidente, considerando os inúmeros processos de defloramentos encontrados. É importante frisar que, em processos dessa natureza, o que estava oficialmente em jogo era a proteção ou condenação da vítima pelo Estado. São observados muitos testemunhos sobre a conduta da ofendida, se esta tinha comportamento "honesto" ou se 
era seu costume "andar sozinha" (ARQUIVO PÚBLICO DO ESTADO RIO GRANDE DO SUL, 1930) ${ }^{3}$. Martha Esteves chama a atenção para o fator socioeconômico nesses comportamentos condenáveis moral e judicialmente: "mesmo nas saídas a serviço, ordenadas pelo patrão, havia o risco potencial de serem levantadas suspeitas quanto à conduta moral da mulher" (ESTEVES, 1989, p. 46). Entretanto, a rua, para a mulher pobre, não era um mistério: era o cotidiano em que a doméstica, lavadeira ou empregada se movimentava pelas ruas e estabelecimentos, livremente, por seu próprio sustento e pelo sustento dos filhos.

Nesse sentido, de todos os tipos de ocorrências noturnas observadas nos processos, os encontros em bares constituem um foco privilegiado de análise. Pode-se observar a forte ligação do conceito "sociabilidade" com os objetivos desta pesquisa:

\begin{abstract}
Na sociabilidade não entram o que as personalidades possuem em termos de significações objetivas, significações que têm seu centro fora do círculo de ação; riqueza, posição social, erudição, fama, capacidades excepcionais e méritos individuais não desempenham qualquer papel na sociabilidade. Quando o fazem, não passam de uma leve nuança daquela imaterialidade com a qual apenas à realidade é permitido penetrar o artifício social da sociabilidade. (SIMMEL, 2006, p. 66).
\end{abstract}

Vale a pena deter-se um pouco mais sobre a ideia de sociabilidade aqui pensada. Simmel defende que o caráter democrático da sociabilidade, principalmente entre pessoas de diferentes estratos sociais, seria um jogo de cena, um artifício social, como supracitado. Nesse sentido, procura-se neste estudo pelos momentos das noites pelotenses em que os preceitos que regiam a sociedade do trabalho e das classes sociais permaneciam, em certa medida, suspensos devido à atmosfera comum que unia pessoas em torno do convívio social. Nas palavras de Simmel (2006),

[...] a igualdade, como vimos, resulta da eliminação, por um lado, do que é inteiramente pessoal, e por outro lado, do que é inteiramente material, ou seja, daquilo que a sociação encontra previamente como seu material e do qual se despe em sua condição de sociabilidade. A democracia da sociabilidade, mesmo entre aqueles socialmente iguais, é um jogo de cena. A sociabilidade cria, caso se queira, um mundo sociologicamente ideal: nela, a alegria do indivíduo está totalmente ligada à felicidade dos outros. Aqui, ninguém pode, em princípio, encontrar sua satisfação à custa de sentimentos alheios totalmente opostos aos seus. (SIMMEL, 2006, p. 69).

\footnotetext{
${ }^{3}$ ARQUiVO PÚBLICO DO ESTADO RIO GRANDE DO SUL. Fundo Comarca de Pelotas. Processo $n^{\circ}$ 1459, Caixa 70, Estante 128B, Subfundo 2a Vara Cível e Crime, 1930. Será utilizada a sigla APERS para designar ao longo do texto o Arquivo Público do Estado do Rio Grande do Sul.
} 
De fato, elemento fundamental da sociabilidade é a reciprocidade. Simmel defende o princípio de que nesses encontros, cada um deve prezar para que cada sentimento em si, seja compatível com a mesma sensação no outro, ou seja, "cada indivíduo deve garantir ao outro aquele máximo de valores sociáveis (alegria, liberação, vivacidade) compatível com o máximo de valores recebidos por esse indivíduo" (SIMMEL, 2006, p. 69 - itálico no original). Portanto, a briga, o conflito e o desentendimento seriam rompimentos com várias instâncias do convívio social. Assim percebido, por exemplo, trazer à tona diferenciações sociais do mundo externo, ferindo o princípio da igualdade (ainda que artificial e efêmera); objetivar a conversa, tornandoa séria e descaracterizando-a enquanto entretenimento social e negando a cortesia, que agrega a leveza do convívio social frente às pressões da realidade.

Outro aspecto que ajuda a entender esses conflitos boêmios é apontado por Heitor Frúgoli (2007), que chama atenção para o quanto a sociabilidade simmeliana pode conter uma linha tênue entre um jogo "entre iguais", enquanto construção artificial e um jogo entre iguais como uma condição prévia:

\begin{abstract}
Ainda que em Simmel as formas de sociabilidade constituam uma esfera marcada pela suspensão momentânea de posições sociais, paradoxalmente as mesmas também permitem uma leitura na direção da formação de círculos "intraclassistas", implícitos na ideia de que tais relações só poderiam efetivamente transcorrer, no interior de um estrato ou segmento social, tornando-se insuportáveis ou dolorosas, quando vividas entre membros de classes sociais distintas, já que pressupõem um mínimo de valores (ou "capital cultural") compartilhados. (FRÚGOLI, 2007, p. 13).
\end{abstract}

Nesse sentido, tem-se a aproximação com autores que defendem uma sociabilidade pautada pela coesão de valores e condição social, além de "pedaços" (MAGNANI, 1984), em que o encontro e o pertencimento seriam pautados por finalidades práticas, ou seja, grupos com certas vulnerabilidades em comum. Entretanto, nesta pesquisa, entende-se a sociabilidade dos bares enquanto lugares que abarcam grupos envoltos em laços sociais verificáveis, mas não somente, pois se percebe a confluência de indivíduos provenientes de variados segmentos sociais ${ }^{4}$. A sociabilidade, nesses espaços, se aproximaria muito mais do temporário "jogo do faz de conta" simmeliano: "faz de conta que são todos iguais, e, ao mesmo tempo, faz de conta que cada um é especialmente honrado." (SIMMEL, 2006, p. 71).

\footnotetext{
${ }^{4}$ Sobre a figura do boêmio enquanto um "anfíbio", capaz de transitar pelo mundo da noite e o mundo do trabalho, ver Benatti (1996). Essa perspectiva é significativa se levarmos em consideração o contexto de adequação do homem pobre e marginalizado, proveniente do mundo rural, à lógica higienizada da primeira metade do século XX, voltada aos ideais urbanos de civilidade e consumo.
} 
É necessário esclarecer a convicção de que, ao referir-se aqui àquilo que Simmel chama de "mundo externo", não significa uma concordância com certas interpretações que se referem ao contexto boêmio como desvinculado de seu papel no mundo do trabalho. Nesta pesquisa, acredita-se, pelo contrário, que o circuito boêmio é uma extensão do mundo do trabalho e, como tal, é palco de resistência, pois é devido ao cotidiano de labor que o tempo noturno consolidou-se como o período privilegiado da sociabilidade e do lazer entre as classes populares. Corroborando o estudo realizado por Luiz Carlos Soares (1999), faz-se necessário frisar que o submundo das atividades noturnas viveu uma maior vigilância policial e administrativa com o advento do século $\mathrm{XX}$, mas nunca com a intenção de extinguir esses hábitos, apenas isolando-os para que continuassem a servir como contraponto da realidade, sem abalar as estruturas da ordem social voltada ao trabalho.

Pode-se afirmar, sem medo, que o submundo das sociabilidades noturnas constitui uma das válvulas de escape mais inerentes ao sistema capitalista. Quanto mais sentida a exploração da lógica de mercado nas sociedades, mais o indivíduo busca no tempo noturno uma conexão social orgânica com seus pares, alguma ligação que não dependa das relações de trabalho e interesses. Eis então, a gama de sociabilidades noturnas que constituem o presente tema de pesquisa. O pesquisador Roberto DaMatta (1983) explora os entrecruzamentos de distintos momentos de nossa sociedade, e utiliza-se, aqui, trecho de seu trabalho para ajudar a explicar a relação do cotidiano com determinados rituais característicos da cultura brasileira:

[...] discutir as peculiaridades de nossa sociedade é estudar também essas zonas de encontro e mediação, essas praças e adros dados pelos carnavais, pelas procissões e pelas malandragens, zonas onde o tempo fica suspenso e uma nova rotina deve ser repetida ou inovada, onde os problemas são esquecidos ou enfrentados; pois aqui - suspensos entre a rotina automática e a festa que reconstrói o mundo - tocamos o reino da liberdade e do essencialmente humano. (DAMATTA, 1983, p. 15).

É necessário alertar para as construções idealizadas do boêmio, enfatizando que a maior parte das produções sobre esse modo de vida acaba por identificá-lo com o mundo do não-trabalho, da rejeição à disciplina e à organização familiar. De fato, parece haver uma clara distinção entre o "boêmio" e o "malandro" na historiografia. Roberto DaMatta (1983) e José Novaes (2001) ligam o malandro à rejeição ao mundo trabalho, às regras e imposições de horários que condicionam a vida do trabalhador. Já o boêmio é mais facilmente identificado com concepções menos radicais, que permitem um 
trânsito maior do indivíduo pelo mundo do trabalho e da malandragem. Contudo, é necessário aludir às ambiguidades inerentes a esses atores, e aos conflitos internos que não raro os acompanham. Nas palavras da autora Maria Izilda Matos (1999), encontrase a tradução de nossas concepções:

O ser boêmio é múltiplo [...] significa viver diferentemente, estabelecer regras de modo distinto, ter uma vida que escape à monotonia e ao previsível, respeitando, contudo, certos códigos estabelecidos nesse universo. Não se entende aqui boemia como um todo fechado, autônomo e homogêneo. A experiência boemia deve ser focalizada de forma relacional, complementar e interdependente à vivência do dia e à do trabalho, e não em confronto a elas. (MATOS, 1999, p. 960).

\section{Conversa de botequim}

Nas ruas do centro, estradas e periferias, ao lado das fábricas e oficinas, junto ao armazém da esquina, pode-se topar com um "kiosque", uma venda ou botequim em cada recanto da cidade. Esses comércios misturam em suas prateleiras gêneros alimentícios, utilitários domésticos e a tradicional "cachacinha", parte indispensável das noites populares. Pretendemos discorrer, nessa seção, sobre como esses espaços de sociabilidade transformaram-se em símbolo e ritual cotidiano das classes populares. As mulheres não eram percebidas no contexto noturno, uma vez que a apropriação desses lugares era predominantemente masculina. No entanto, na busca por suprimentos e víveres necessários ao trabalho ou ao âmbito doméstico de suas casas, elas tinham no armazém, também um ponto diário de sociabilidade, necessário e mantenedor de suas identificações no interior do grupo social. Pelo menos, desde o século XIX, pode-se identificar a presença e a característica desses pequenos estabelecimentos, em que se comercializavam alguns suprimentos básicos e, à noite, reuniam-se homens nos balcões, a conversar e beber, prostitutas em busca de clientes ${ }^{5}$ e demais agentes sociais em busca de um espaço para suas expressões culturais e desabafos cotidianos. Na visão das classes abastadas e autoridades das primeiras décadas do século XX, esses espaços não eram vistos com bons olhos, como revela a pesquisa de Maria Izilda Matos (2001):

\footnotetext{
5 Sobre esta afirmação é necessário esclarecer que, para as prostitutas, o botequim estava também relacionado à rotina de trabalho e sobrevivência, tendo a sociabilidade noturna outro significado. Assumese que, apesar do rico material passível de análise - ou, justamente por isso -, optou-se por não abordar a questão de forma tangencial, deixando a utilização das fontes para uma pesquisa dedicada especificamente ao assunto.
} 
O processo de urbanização e industrialização criava a necessidade de diferenciar espaços, cristalizando divisões cada vez mais claras no urbano. $\mathrm{O}$ controle social passou a atingir diferentes esferas do cotidiano, em particular das camadas populares, tendia-se a ordenar as situações de trabalho e de lazer, crescendo a vigilância sobre os espaços de lazer popular como o botequim, território majoritariamente masculino, no qual, em momentos de descanso, a conversa informal brotava em torno do balcão ou da mesa, tomando alguma bebida, café, cachaça ou cerveja. $\mathrm{O}$ discurso médico acompanhou tais mudanças, apresentando o bar, cabaré e botequim, em contraposição à fábrica, à oficina e ao escritório, espaços do trabalho, e ao espaço do lar. Considerava-se que esses espaços de lazer encorajavam a indisciplina e libertinagem, neles se misturavam sociabilidade, violência, prazer e desordem, causando problemas no trabalho e a ruína doméstica. (MATOS, 2001, p. 75).

Nesses locais, que podiam ser bares, casas comerciais, armazéns ou quiosques, encontram-se uma série de elementos que compõem e reforçam o imaginário social masculino. Conversas, bebidas, jogos e camaradagem, num clima pretensamente democrático, mas sensível a todas as diferenciações étnicas, sociais e culturais, transformam esses espaços em locais privilegiados para a análise de sociabilidades e conflitos.

Dentre os motivos que aparecem como estopins em brigas e discussões para o início da violência, estão discussões sobre "Foot-Ball", sobre quem era mais homem, trapaças, jogos a dinheiro (APERS, 1937) ${ }^{6}$, além, é claro, das bebidas alcoólicas, que aumentavam as proporções de cada divergência (APERS, 1930) ${ }^{7}$. A honra, a injúria e as ofensas pessoais levavam a reações extremadas dos homens pobres e trabalhadores da década de 1930. Tanto a falta do trabalho quanto a fadiga de um cotidiano de labor podiam tecer o pano de fundo para brigas e discussões, ou para o vício tradicional do "trago de cachaça", o que acaba por endossar a hipótese aqui apresentada, de um universo boêmio que carrega consigo o vínculo com o mundo do trabalho. Os bares eram cenário frequente de conflitos, significando, ao mesmo tempo, local de camaradagem e espaço de disputa e afirmação dos valores masculinos da época. Era ali que afogavam as mágoas, discutiam futebol, cantavam seus amores e divagavam ao som do gramofone, a tal ponto que se perdiam os detalhes de uma briga na mesa ao lado

\footnotetext{
${ }^{6}$ ARQuivo PÚblico do eStado RIO GRANDE do SUl. Fundo Comarca de Pelotas. Processo $n^{\circ}$ 1582, Caixa 80, Estante 140D, Subfundo $1^{\text {a }}$ Vara Cível, 1937.

${ }^{7}$ ARQuivo Público do estado RIO GRANDE do SUl. Fundo Comarca de Pelotas. Processo

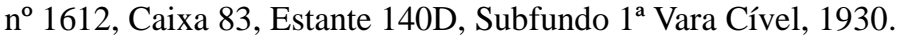

${ }^{8}$ Ou o "mé", termo encontrado por Magnani (1984) em etnografia baseada na periferia de São Paulo da década de 1970. Designava, para os nativos, a ingestão de bebidas alcoólicas ao fim da jornada diária de trabalho, ritual que unia os homens no bar e consolidava, com o encontro informal, a comunidade de colegas e vizinhos.
} 
$\left(\right.$ APERS, 1932) ${ }^{9}$. Questiona-se, hoje, se tamanho enleio seria provocado realmente pela sedutora música que se espraiava em ondas, ou se tal afirmação fazia parte de um conjunto de estratégias utilizadas pelos populares, a fim de se esquivar das obrigações com a polícia e a justiça.

Entretanto, não se pode esquecer que o bar também era lugar de confraternização e cumprimentos alegres, rodadas de bebidas entre amigos e alguém a tocar modinhas num violão. É claro que, ao menor sinal de contenda, o violão transformava-se em uma arma, como bem o utilizou Manoel Pedro Soares. Guido Ventana havia iniciado uma discussão sobre quem era mais homem e perturbava a tranquilidade daquele bar do interior, ao que Manoel interrompeu a execução das músicas para empreender mais urgente utilidade ao violão... (APERS, 1930) ${ }^{10}$.

Há também a possibilidade de conflitos étnicos no interior do bar. Como bem afirmou Karl Monsma (2004) em suas pesquisas sobre negros e europeus no interior paulista, se tratando de imigrantes e brasileiros, o cuidado teria de ser redobrado. Ao mínimo sinal de discriminação ou um comportamento não condizente com a atmosfera democrática e igualitária que regia as sociabilidades boêmias, o estremecimento estava feito. Talvez Guido Brughski (vítima) não tivesse ideia do que sua atitude poderia acarretar quando favoreceu seus clientes alemães no bar em detrimento de outro cliente não pertencente à ascendência germânica. Atacado a punhaladas, na manhã após ter expulsado Mario José da Cunha do bar, sentiu na carne o fio de seus atos (APERS, $1933)^{11}$.

E ainda, dentre as brigas em bares, encontra-se o tipo de contenda que só personagens como "Zéca Taco" podem protagonizar. Na noite de dezesseis de dezembro de 1931, esse "conhecido gatuno" apareceu na Casa Comercial de Ulysses Teixeira (R. Três de Maio, 269), por volta das vinte e uma horas, esbravejando contra João Lopes, que se encontrava no recinto, e agrediu-o fisicamente, devido a desentendimentos referentes a uma "petiça". Este acabou ferido por um ataque de adaga desferido por João (APERS, 1931) $)^{12}$.

\footnotetext{
${ }^{9}$ ARQUivo PÚBlico do ESTAdo RIO GRANDE do SUl. Fundo Comarca de Pelotas. Processo n 1568 , Caixa 79, Estante 128B, Subfundo $2^{\circ}$ Cível e Crime, 1932.

${ }^{10}$ ARQUIVO PÚBliCo do ESTAdo RIO GRANDE DO SUL. Fundo Comarca de Pelotas. Processo $n^{\circ} 1666$, Caixa 87, Estante 128B, Subfundo $2^{\circ}$ Cível e Crime, 1930.

${ }^{11}$ ARQUiVo PÚBliCo dO ESTADO RIO GRANDE DO SUL. Fundo Comarca de Pelotas. Processo n 1646, Caixa 84, Estante 128B, Subfundo $2^{\circ}$ Cível e Crime, 1933.

${ }^{12}$ ARQUiVo PÚBLICO DO ESTADO RIO GRANDE DO SUL. Fundo Comarca de Pelotas. Processo $n^{\circ}$ 1566, Caixa 79, Estante 128B, Subfundo $2^{\circ}$ Cível e Crime, 1931.
} 
Um dos elementos dessa típica sociabilidade masculina, a conversa, pode ser particularmente analisada nesses contextos, pois tem uma dinâmica significativa no desenrolar da sociabilidade noturna dos botecos. A conversa, na sociabilidade, tem como seu fim o entretenimento e a ligação dos indivíduos ao momento do convívio social, servindo para manter os preceitos e protocolos em jogo, sem que se rompa o artifício igualitário desses espaços. Assim, o assunto não é o que realmente importa, desde que se sigam os modelos de interações socialmente aceitos, pois, como alega Georg Simmel, a conversa é a miniatura do ideal de sociedade, portanto, abriga em seu desenrolar as aproximações e dilemas aos quais correspondem determinadas posturas de parte dos interlocutores. Em destaque o trecho explicativo abaixo:

\begin{abstract}
Na conversa puramente sociável o assunto é somente o suporte indispensável do estímulo desenvolvido pelo intercâmbio vivo do discurso enquanto tal. Todas as formas pelas quais essa troca se realiza - como o conflito e o apelo a ambas as partes para que atendam às normas reconhecidas, o acordo de amizade por meio do compromisso e a descoberta de convicções comuns, o acolhimento de bom grado do que é novo e a recusa daquilo sobre o qual não se pode esperar nenhum entendimento -, todas essas formas de interação da conversa, que de resto estão a serviço de inúmeros assuntos e finalidades das relações humanas, têm aqui seu significado em si mesmas, quer dizer, no estímulo do jogo da relação que elas estabelecem entre indivíduos que se unem ou se separam, que vencem ou subjugam-se, recebem ou dão (SIMMEL, 2006, p. 75).
\end{abstract}

Assim como a conversa, nesses espaços de sociabilidade, tem um fim em si mesma, ou seja, não tem o intuito de levar a algum lugar se não à própria sociabilidade a que esta se insere; o jogo a dinheiro, nesses circuitos, também não carrega o objetivo exclusivo de se ganhar dinheiro, mas sim, de permanecer, coletivamente, à mercê lúdica dos dados e do acaso das cartas e apostas. É significativo notar que quase todos os botequins mencionados nos processos dispunham de uma sala nos fundos, ou algum recinto reservado para essas práticas. Apesar de não serem poucos os casos de brigas nos botequins que apresentam alguma menção ao jogo ${ }^{13}$, verifica-se apenas um processo de ocorrência noturna em que a polícia comparece ao clube "Fica Ahi" para coibir a prática dos jogos e apostas a dinheiro (APERS, 1930) ${ }^{14}$. É bastante provável que o jogo se constituísse, na sociedade das primeiras décadas do século XX, como a prostituição, como a definiu Luiz Carlos Soares (1999), ou seja, uma parte da noite a ser controlada,

\footnotetext{
${ }^{13}$ Alguns chegam a tratar de casos de assassinato após desentendimentos no jogo, como é o caso do processo $\mathrm{n}^{\mathrm{o}}$ 1582, Caixa 80, Estante 128B, Subfundo $2^{\mathrm{a}}$ Vara Cível e Crime, Fundo Comarca de Pelotas, do Arquivo Público do Estado do Rio Grande do Sul, 1937.

${ }^{14}$ ARQuivo PÚblico do estado RIO GRANDE do SUl. Fundo Comarca de Pelotas. Processo $n^{\circ}$ 1612, Caixa 83, Estante 128B, Subfundo 2 2ara Cível e Crime, 1930.
} 
vigiada, mas não efetivamente eliminada.

Não por acaso, a metáfora do jogo é escolhida por Simmel para explicar as atuações e protocolos identificáveis na sociabilidade. O jogo social, como exprime o autor, abrange essas miniaturas da vida em sociedade, em que, libertos dos pesos da hierarquia e da responsabilidade do mundo externo, todos atuam em uma espécie de leveza suspensa, uma pretensa igualdade de posições típica da sociabilidade. No entanto, sabe-se que, eventualmente, a conversa ou o jogo são levados a sério, e acabam por trazer à tona fundamentações de verdade baseadas no mundo material, quebrando o encanto deste frágil equilíbrio.

Perceber o quanto estes circuitos noturnos de sociabilidade nos bares e botequins configuram rituais cotidianos é fundamental para bem situar as noites boêmias no cotidiano do brasileiro. De acordo com DaMatta (1983, p. 47), é possível afirmar que "as posições sociais ocupadas no quotidiano são neutralizadas ou invertidas: os rituais populares são ritos que objetivam o encontro, não a separação". Ainda que as noites de Pelotas, sob o olhar aqui observado, desnudem uma série de componentes de desagregação no interior dessas sociabilidades, estamos, sim, falando de rituais populares de identificação. Sidney Chalhoub (2001), há quase trinta anos, já atentava para a importância do espaço social do botequim para o estudo das classes populares, e conclui, aqui, esse raciocínio:

\footnotetext{
Com efeito, a venda ou botequim é cenário para o surgimento e desenrolar de rixas e conflitos pelos mais variados motivos, desde os problemas ligados ao trabalho e habitação, passando pelas questões de amor e de relações entre vizinhos, até as contendas por motivos mais especificamente ligados ao lazer, como os jogos, o carnaval ou a bebida. (CHALHOUB, 2001, p. 312).
}

O hábito do botequim, ao fim do dia, não só representa uma característica essencial do cotidiano dos trabalhadores brasileiros, como é presente também nas análises sobre a vida cultural noturna pelotense, ainda que essa região adquira um outro contorno favorável ao trago de cachaça, tendo em vista as baixas temperaturas no inverno. Em trabalho anterior, pesquisa que permeou o contexto das serestas nas décadas de 60 e 70 do século passado em Pelotas, no qual foram desenvolvidas entrevistas com os músicos e em relatos orais, percebeu-se o quanto essa característica está arraigada por décadas a fio entre esses circuitos boêmios: "peguei muita gripe com serenata... (risos) Ah, é, porque era inverno e verão e no inverno era brabo. É que pra aquecer, a gente tinha que tomar uns 'traguinhos'... Aí tomava demais, aquecia demais 
e já não tocava nada" (AVENDANO JR apud. CARVALHO, 2010, p. 41).

O trabalho de José Cantor Magnani vai ao encontro dessa afirmação com as observações sobre o lazer dos populares nas periferias de São Paulo, na década de 1970, século XX. O autor também encontra conservado o rito de passagem do botequim como configuração essencial da aceitação masculina entre os populares das grandes cidades e vivenciou tal episódio como um divisor de águas para sua completa inserção no campo -, mas enfatiza que os tragos, ou més, na linguagem dos "nativos", tem mais valor simbólico para a irmandade do "pedaço" do que o valor funcional de alcoolizarse:

\begin{abstract}
Os bares [...] costumam ser frequentados exclusivamente por homens que se encontram para "tomar um mé" depois do trabalho ou nos fins de semana. Só no núcleo de Três Corações e suas proximidades pude contar, aproximadamente, uns quinze bares, quase todos com sinuca, alguns com baralho e dominó nos fundos. Isso não significa que a população da vila seja viciada e alcoólatra: o "mé", a sinuca, o dominó e o carteado são antes de mais nada ocasiões de encontro dos diferentes grupos de coleguismo e vizinhança. Basta lembrar o ritual de reconhecimento e aceitação para compreender a importância desses encontros para o estabelecimento e reforço das relações grupais. (MAGNANI, 1984, p. 143).
\end{abstract}

É interessante continuar a reflexão sobre o ritual do botequim para o trabalhador do início do século passado, tomando como base alguns pensamentos de DaMatta (1983), acerca da rotina dos brasileiros:

\footnotetext{
Não há sociedade sem uma ideia de um mundo extraordinário, onde habitam os deuses e onde, em geral, a vida transcorre num plano de plenitude, abastança e liberdade. Montar o ritual é, portanto, abrir-se para esse mundo, dando-lhe uma realidade, criando um espaço para ele e abrindo as portas da comunicação entre o "mundo real" e o mundo especial. (DAMATTA, 1983, p. 32).
}

Evidencia-se aqui a importância dos hábitos noturnos da boemia e do botequim para a cultura popular brasileira. Tão claro está que é possível, sem dúvida, propor que esse hábito cotidiano foi elevado, ao longo das décadas, ao estatuto de ritual. Em alguns períodos mais condenado, em outros, vigiado, mas o ritual notívago de diversão, camaradagem e prazer perpetua-se através do tempo, e agrega pessoas de diversos setores sociais, ao redor de um mesmo ideal de lazer, descanso e domínio sobre as próprias escolhas. "Nesse sentido, o ritual é algo plenamente compatível com o mundo da vida diária e os elementos do mundo diário são os mesmos elementos do ritual" (DAMATTA, 1983, p. 55). 
Portanto, não se quer dizer aqui, que o ritual boêmio é âmbito de inversão de status sociais ou de comunhão entre as classes, mas sim, que significa um momento do dia em que as aspirações de igualdade, bem-estar e lazer, independente de quaisquer classificações, salientam-se. A noite da boemia é o momento do dia em que os desejos de cumplicidade e solidariedade entre os indivíduos ficam mais evidentes, e é precisamente ao quebrar essa sensível ideia de irmandade noturna que ocorrem os conflitos.

É notável perceber o quão frágeis são essas bases, pois, muitas vezes, percebemse conflitos no botequim provocados por simples menções que trazem à tona diferenciações sociais do "mundo real". No caso do crime no Restaurante Guido, localizado no centro da cidade, temos uma situação exemplar, em que inúmeras referências a diferenças étnicas e sociais são abordadas no bar, culminando com agressões e a expulsão de um de seus frequentadores. Mário José da Cunha sentou-se e bebia sozinho em uma mesa do bar. O dono do bar, Guido Brughski, e alguns amigos de ascendência alemã, Dr. Carlos Hofmann (cirurgião dentista) e Alberto Heilsmann, bebiam e conversavam, em alemão, na mesa ao lado. Tal segregação de parte destes últimos, expressa pelo uso de um idioma incompreensível por Mário, e pelo fato de não se haver cumprido com os rituais dessa sociabilidade, como a conversa, a aproximação e o caráter agregador, fez com que se criasse uma animosidade no ambiente e, mesmo após o convite para o jogo, mantivesse uma tensão no ambiente, em que Mário, possivelmente, permanecia com a impressão anterior de ter sido, de certa forma, discriminado pelos demais. Devido a desacordos no jogo, Mário acabou agredindo um dos alemães, amigos de Guido, e este o expulsou de seu estabelecimento. Mário, tendo sua honra ofendida, muniu-se de uma faca e retornou às imediações do bar, onde se pôs a esperar, pacientemente, até que o Restaurante reabrisse. Por volta do meio-dia, na manhã seguinte, Mário caminhou até o bar e pediu para falar com Guido e, quando este apareceu, Mário desferiu inúmeros golpes no comerciante, ferindo-o substancialmente, levando-o a óbito (APERS, 1933) ${ }^{15}$.

O pesquisador Karl Monsma (2004), já mencionado, atenta para as relações interétnicas, pois as visões de hierarquia de diferentes grupos étnicos não se baseavam nos mesmos preceitos. Enquanto os negros consideravam as escalas profissionais, baseadas nas chefias e cargos subordinados e presumiam, em situações no espaço

\footnotetext{
${ }^{15}$ ARQUiVo PÚBLICO DO ESTADO RIO GRANDE dO SUL. Fundo Comarca de Pelotas. Processo $n^{\circ}$ 1646, Caixa 84, Estante 128B, Subfundo $2^{\circ}$ Cível e Crime, 1933.
} 
público, que todos estivessem em posição de igualdade, os europeus tinham tendência a relacionar a cor da pele como o marco das relações de subordinação. Conforme o autor, eles "tendiam a perceber a cor como um esquema matriz de categorização, prevalecendo sobre todos os outros, e de enfatizar suas associações hierárquicas, ligando a pele escura com características negativas como estupidez, paganismo, preguiça ou alcoolismo" (MONSMA, 2004, s/p.). Talvez, tomando-se esta lógica para o caso em questão, Mário não fosse "suficientemente branco" para ser previamente respeitado e valorizado entre os presentes no bar, embora na descrição da ocorrência a cor de sua pele não seja especificada.

De fato, na situação analisada sobre a noite de dezesseis de setembro de 1933, no Restaurante Guido, parece que a diferenciação social teve papel muito mais significativo, no momento em que os presentes no bar não cumpriram com o ritual da sociabilidade boêmia de camaradagem e respeito mútuo, de observação e atuação no jogo social. Com isso, acabaram por ferir sensivelmente o princípio de irmandade que deve prevalecer nesses espaços tão importantes da socialização masculina. Porém, é necessário atentar para as outras formas de distinções criadas, a partir da convivência e do véu de igualdade inicial. Como destaca Jardim (1991)

[...] do ponto de vista dos homens que frequentam os butecos, o reconhecimento de uma igualdade entre os frequentadores não elimina a possibilidade de diferenças e hierarquias nas relações; pelo contrário, possibilita que essas hierarquias estejam em jogo durante as interações. É ali, mesmo através do reconhecimento entre as distâncias e distinções, que se estabelecem cumplicidades entre os homens. Do ponto de vista de um sistema baseado na honra, e coerente com ele, os participantes destas conversas nos butecos devem se reconhecer como iguais para participar dos eventos, o que não significa que suas posições não estejam sendo demarcadas durante as conversas. É a honra e a posição conquistada frente aos outros, o que está sendo disputado. ${ }^{16}$ (JARDIM, 1991, p. 92).

Como se o ritual boêmio do bar ou botequim fosse um espaço privilegiado no qual, apesar de reunir diferentes indivíduos, com diferentes opiniões, rotinas e visões de mundo, o ritual noturno de ouvir, contar e compartilhar momentos, angústias e alegrias (além de alguns brindes) tivesse a capacidade de recriar posições, qualificaçõoes e distinções entre seus participantes. Ao uni-los em torno das mesmas imposições - a lógica moderna e industrial do trabalho, da regulação nos hábitos e nos comportamentos, as pressões do provimento familiar e da relação marital, etc. -, o ritual

\footnotetext{
${ }^{16}$ É pertinente destacar a grafia da palavra boteco, preferida pela autora como "buteco", no intuito de aproximar a expressão da linguagem coloquial.
} 
masculino da recompensa por mais um dia árduo de labuta, ressignificava as relações entre os homens. Para se chegar a essa imagem, é preciso enxergar o cotidiano como momento pleno de carga simbólica e significações profundas na identidade social das classes populares. Nas palavras de DaMatta (1983, p. 60), constata-se que

[...] o estudo dos rituais não seria um modo de procurar as essências de um momento especial e qualitativamente diferente, mas uma maneira de estudar como elementos triviais do mundo social podem ser deslocados e, assim, transformados em símbolos que, em certos contextos, permitem engendrar um momento especial ou extraordinário. (DAMATTA, 1983, p. 60).

Afinal, por tudo já discorrido aqui sobre a cultura popular, é possível perceber esses atores sociais, enquanto participantes de "formas sociais próprias e independentes, mesmo que forjadas continuamente, na verdade, pela dialética entre os projetos ou modelos culturais feitos para ela e aqueles engendrados a partir de sua prática real de vida" (CHALHOUB, 2001, p. 303).

É notável e necessário reforçar a característica da cidade de Pelotas, principalmente no período estudado, ao acolher uma gama considerável de habitantes advindos dos meios rurais em busca de melhores oportunidades. No entanto, não se refere, no presente estudo, à nova realidade do migrante, enquanto uma via de mão única, em que este é continuamente forjado pelos hábitos urbanos, mas sim, “o migrante como um ator social, num sentido, destribalizado (ao tomar posição numa estrutura urbana de relações sociais) e, noutro, desurbanizado (ao retomar continuamente o sistema rural (tribal) e seu jogo de regras)" (FRÚGOLI JR., 2007, p. 41). Adaptando este trecho à realidade pelotense analisada, são agora compreensíveis os meandros que permitiram à cidade permanecer, tanto com uma aspiração cosmopolita, quanto com um jeito provinciano de viver, ou seja, percebe-se a confluência de lógicas da modernidade, provenientes de seus vínculos com o Rio de Janeiro, o exterior e os países platinos, e, ao mesmo tempo, a sobrevivência de valores ligados a um passado rural, de honras e costumes antigos.

Esse caráter atribuído aqui, à cidade de Pelotas, emprestava aos seus boêmios da década de 1930, uma heterogeneidade de valores e sentimentos, os quais acabavam por produzir, muito facilmente, conflitos nos encontros notívagos de sociabilidade. Apesar de facilmente produzidos, sabe-se que tinham implicações sérias à reputação destes homens em seu grupo social. Portanto, enfatiza-se neste trabalho, que dentro de 
discussões sobre "quem era mais homem" (APERS, 1930) ${ }^{17}$ ou em uma "divergência sobre Foot-Ball" (APERS, 1930) ${ }^{18}$ estavam inseridas concepções importantes que definiam quem é quem no jogo da sociabilidade masculina popular.

A presença constante e, às vezes, determinante, dos tragos de cachaça no desfecho dos desentendimentos, alerta para um aspecto histórico importantíssimo, pois, diferentemente dos dias atuais, em que a embriaguez é considerada um agravante jurídico nas autuações, na década de 1930, era possível que a alegação de embriaguez atenuasse de tal forma a culpabilidade do réu em uma agressão seguida de morte, que este acabasse por ser absolvido ou, no mínimo, que os lapsos de memória nos depoimentos fossem vistos sob um olhar, se não solidário, indulgente.

Aliás, com relação à "cachacinha", não é forçoso identificá-la como a protagonista nos botequins. Com ela selavam-se amizades, introduziam-se os novatos no microgrupo do bar e animavam-se os mais quietos. Os "traguinhos" para aquecer também eram os tradicionais salvadores das noites mais frias, conforme visto anteriormente. Por isso, e por tanta importância enquanto mantenedor das noites boêmias dos bares, o hábito da cachaça era difícil de eliminar, como tencionavam as propagandas médicas pesquisadas por Maria Izilda Matos (2001) e como sugeriam algumas medidas administrativas encontradas por José Plínio Fachel (apud. GERTZ, 2005, p. 143) sobre o carnaval do ano de 1941 na região de Pelotas, que orientavam: “durante os dias de carnaval fica proibida a venda de bebidas alcoólicas em bares, hotéis, restaurantes, cafés, botequins e mercadinhos, excetuando-se o vinho, chopp, cerveja, whisky e champagne". A resolução chega a ser motivo de riso, pois utiliza de artifícios de linguagem para mascarar a proibição exclusiva da cachaça.

Enfim, foi exposto aqui um breve panorama da sociabilidade noturna dos "kiosques", cafés e casas comerciais que abrigavam os boêmios da década de 1930, em Pelotas, lugares em que esses notívagos expressavam seus valores, sua cultura e sua identidade social. Nessa mescla de cultura e honra, residiam seus códigos de conduta, que se mostraram herdeiros do imaginário popular sobre si mesmos, das assimilações e recusas às noções de civilidade do mundo moderno e de um cotidiano de hábitos simples e costumes antigos, que tentava buscar seu espaço em uma cidade inclinando-se

\footnotetext{
${ }^{17}$ ARQuivo PÚblico do eSTAdo RIO GRANDE DO SUL. Fundo Comarca de Pelotas. Processo $n^{\circ}$ 1666, Caixa 87, Estante 128B, Subfundo 2 Cível e Crime, 1930.

${ }^{18}$ ARQuivo PÚBlico do estado RIO GRANDE do SUl. Fundo Comarca de Pelotas. Processo no 1562, Caixa 79, Estante 128B, Subfundo 2 2ara Cível e Crime, 1930.
} 
cada vez mais à lógica de mercado. Chalhoub (2001) expressa com maestria esta conjuntura:

\begin{abstract}
Os homens para se comunicarem, para transmitirem mensagens, utilizam-se dos códigos existentes e que são resultado de trabalho humano passado códigos estes que, logicamente, possuem dimensão histórica e se transformam continuamente. [...] os populares estavam imbuídos de normas próprias reguladoras de suas desavenças, possuíam noções próprias de justiça e, quando envolvidos em situações de conflito, seguiam rituais de conduta que mostravam apego a valores muitas vezes opostos àqueles prezados pelas classes dominantes. (CHALHOUB, 2001, p. 308).
\end{abstract}

Escolheu-se, para o encerramento das análises, um trecho no qual Simmel (2006) capta o significado preciso da carga simbólica que adquiriam estas noites para estes homens pobres, jovens ou chefes de família, buscando um pertencimento social e o momento coletivo para esquecer as agruras do cotidiano:

Para muitos homens que sentem a cada momento a profundidade e a pressão da vida, a sociabilidade não poderia ter essa alegria libertadora e redentora se ela fosse somente a fuga desta vida, ou uma suspensão meramente momentânea de sua seriedade. De várias maneiras, a sociabilidade pode ser esse elemento negativo, um convencionalismo e uma troca internamente estéril de formas. [... No entanto], é exatamente o homem mais sério que colhe da sociabilidade um sentimento de libertação e alívio. Porque ele desfruta, como numa representação teatral, de uma concentração e de uma troca de efeitos que representam, sublimadas, todas as tarefas e toda a seriedade da vida. A um só tempo, também, as dissolve, porque as forças da realidade carregadas de conteúdo soam como que ao longe, deixando desvanecer seu peso e convertendo-se em estímulo. (SIMMEL, 2006, p. 82).

\title{
Considerações finais
}

Percebe-se, no contexto da década de 1930, em Pelotas, um espaço urbano em expansão, com o desenvolvimento das zonas periféricas da cidade e o surgimento de residências e casas comerciais espalhadas por esses territórios, os quais ganhavam maior acessibilidade com o consequente acompanhamento das linhas dos bondes, o que refletia a demanda em ascensão. Data desse período, também, uma série de investimentos estruturais, bem como a presença ativa da energia elétrica e o surgimento de novas dinâmicas cotidianas ligadas às inovações propiciadas com a atenção da indústria sobre a criação de novos hábitos e produtos.

Cabe lembrar as constatações, mencionadas no trabalho aqui desenvolvido, a respeito das transformações no funcionamento do capitalismo, sinalizando um momento de transição para um sistema voltado ao consumo, que impunha, dessa maneira, um 
enfoque essencial na organização familiar e na ordem do trabalho, uma vez que assim eram conduzidas as produções de necessidades e desejos na vida da população, o que viabilizava a manutenção do sistema capitalista. Tais considerações concernentes ao contexto vivenciado na década de 1930 permitiram um entendimento esclarecido acerca das transformações que permeavam o cotidiano dos populares, para que fosse possível perceber, na fase de análise das ocorrências policiais, as estratégias e escolhas desse setor social, diante de um contexto cuja crescente fiscalização de seus hábitos era inegável. A vida noturna era vigiada com maior regulação, no entanto é significativo que os espaços de sociabilidade noturna, casas de tolerância e jogos, raramente chegavam a sofrer repressões extremas, como o fechamento. Identificou-se um procedimento padrão de reprimir os excessos e controlar o espaço limítrofe de ação desses locais, mantendo-os à parte da lógica diurna de trabalho e ordem social.

As atenções referentes à contextualização tornaram-se ainda mais importantes devido à característica múltipla do objeto aqui estudado. Pesquisou-se o tempo noturno, no entanto, não de maneira irrestrita, uma vez que se imputou a situação de sociabilidade enquanto o mote principal, fazendo com que parte das ocorrências encontradas fosse apenas mencionada, sem participar da análise. E, por último, tem-se o cotidiano popular como direcionador dessa busca, pois se pretende compreender, justamente, de que forma a "gente comum", as pessoas simples, divertiam-se e escolhiam passar seu tempo livre em situações de convívio social. À procura de noites democráticas e acessíveis, buscou-se nos processos criminais perceber esses três elementos combinados: noite, boêmios e sociabilidade. Setores desfavorecidos da classe média e camadas pobres da população contribuíram para uma movimentação noturna na cidade que revela, desde as primeiras décadas do século XX, parâmetros de conduta e convivência social específicos das classes populares.

Enfatiza-se aqui o campo das lutas de classificação e reforços identitários diários, como parte de um cotidiano simbólico, ressaltado em situações de sociabilidade e conflito. A ideia masculina de honra, por exemplo, é verificada como uma das formas populares para conseguir e manter o respeito dos demais presentes nesses encontros cotidianos e diversões das classes despossuídas. Verificou-se que havia, predominantemente, a superposição desses códigos de conduta dos meios populares sobre a lógica da lei e da justiça oficial, ou seja, esses homens preocupavam-se em defender ou reparar publicamente a sua honra a ponto de relegarem a segundo plano, a possibilidade de serem presos. 
Constituiu aspecto importante nessa análise, identificar a expressão do êxodo rural para o período estudado. Juntamente com os contingentes populacionais advindos do interior do município, uma lógica provinciana permanecia ligada aos círculos noturnos da cultura popular, ao mesmo tempo em que valores ligados às noções de civilidade eram gradativamente apropriados, constituindo uma via de mão dupla entre a dicotomia rural - urbano.

O bar, botequim, casa comercial ou quiosque foram percebidos no contexto noturno, como o principal espaço da sociabilidade popular masculina. Nesses locais, os homens das classes populares - tanto da zona urbana quanto rural - encontravam-se para o ritual diário de suspensão das pressões cotidianas e cultivo da camaradagem masculina. Ali, revelavam-se todos os passos para a inserção dos novatos e forasteiros, havendo uma política inicial de cortesia ao mesmo tempo em que era considerado merecimento de respeito o sujeito não fugir a uma briga ou provocação. Percebeu-se, assim, embora a verificação frequente de conflitos, o ritual popular do botequim como um hábito de aproximação entre os homens de diferentes locais, revelando um costume em comum, com o objetivo de conhecer e agregar, e não de estabelecer distinções, noção essencial para a compreensão de uma lógica popular, com preceitos fundamentalmente diferentes daqueles que pautavam as sociabilidades das elites.

Conclusão marcante deste trabalho foi enxergar a noite popular enquanto um circuito de sociabilidade masculina, ou seja, voltada à afirmação e identificação social dentro desses microgrupos boêmios, como o bar, os cafés e casas comerciais, discutidos e analisados com base nos casos encontrados na pesquisa com os processos criminais. Em outras palavras, os códigos ligados a esses setores da sociedade, suas reações mais instintivas e aparentemente naturais, revelavam um sistema intrincado de relações e associações referentes, ao mesmo tempo, à posição dos populares na estrutura social não dispunham de recursos materiais para usufruir na hierarquia social, daí a importância da honra e do respeito -, e à sua bagagem cultural, onde tais hábitos eram passados de geração a geração, agregando uma simbologia das noites para o reconhecimento desses homens entre si e em relação ao pertencimento no grupo.

Permeadas por códigos de conduta, por elos da cultura popular e espaços privilegiados de ação, as noites de Pelotas na década de 1930, já mostravam o universo de relações que compunha o tempo noturno do lazer popular, trazendo à tona inúmeros ângulos possíveis de observação e aprendizado. 


\section{REFERÊNCIAS}

\section{Fontes primárias}

ARQUIVO PÚBLICO DO ESTADO RIO GRANDE DO SUL. Fundo Comarca de Pelotas. Processo ${ }^{\circ}$ 1459, Caixa 70, Estante 128B, Subfundo $2^{\text {a }}$ Vara Cível e Crime, 1930.

ARQUIVO PÚBLICO DO ESTADO RIO GRANDE DO SUL. Fundo Comarca de Pelotas. Processo $\mathrm{n}^{\mathrm{o}}$ 1562, Caixa 79, Estante 128B, Subfundo $2^{\mathrm{a}}$ Vara Cível e Crime, 1930.

ARQUIVO PÚBLICO DO ESTADO RIO GRANDE DO SUL. Fundo Comarca de Pelotas. Processo ${ }^{\circ}$ 1612, Caixa 83, Estante 128B, Subfundo 2a Vara Cível e Crime, 1930.

ARQUivo PÚBLICO DO ESTADO RIO GRANDE DO SUL. Fundo Comarca de Pelotas. Processo n ${ }^{\circ}$ 1612, Caixa 83, Estante 140D, Subfundo $1^{\text {a }}$ Vara Cível, 1930.

ARQUivo PÚBLICO DO ESTADO RIO GRANDE DO SUL. Fundo Comarca de Pelotas. Processo n 1666, Caixa 87, Estante 128B, Subfundo 2 Cível e Crime, 1930.

ARQUivo PÚBliCO DO ESTADO RIO GRANDE DO SUL. Fundo Comarca de Pelotas. Processo n ${ }^{\circ}$ 1566, Caixa 79, Estante 128B, Subfundo $2^{\circ}$ Cível e Crime, 1931.

ARQUIVO PÚBLICO DO ESTADO RIO GRANDE DO SUL. Fundo Comarca de Pelotas. Processo nº 1568, Caixa 79, Estante 128B, Subfundo 2º Cível e Crime, 1932.

ARQUivo PÚBliCO DO ESTADO RIO GRANDE DO SUL. Fundo Comarca de Pelotas. Processo n 1646, Caixa 84, Estante 128B, Subfundo 2 Cível e Crime, 1933.

ARQUivo PÚBliCO DO ESTADO RIO GRANDE DO SUL. Fundo Comarca de Pelotas. Processo $n^{\circ}$ 1582, Caixa 80, Estante 140D, Subfundo $1^{\text {a }}$ Vara Cível, 1937.

\section{Fontes secundárias}

BENATTI, Antonio Paulo. O centro e as margens: boemia e prostituição na "capital mundial do café" (Londrina-PR, 1930-1970). 1996. Dissertação (Mestrado em História) - Universidade Federal do Paraná, Programa de Pós-graduação em História, Curitiba, 1996.

BORGES, Geruza Esteves. A energia elétrica como campo de pesquisa: os primórdios da eletrificação em Pelotas (1914-1916). 2008. Trabalho de Conclusão de Curso (Licenciatura em História) - Universidade Federal de Pelotas, Departamento de História, Pelotas, 2008.

CARVALHO, Thaís de Freitas. Um lugar chamado liberdade: música, tradição e boemia em Pelotas. 2010. Monografia (Trabalho de conclusão de Curso) - Universidade Federal de Pelotas, Departamento de História, Pelotas, 2010. 
CHALHOUB, Sidney. Trabalho, lar e botequim: o cotidiano dos trabalhadores no Rio de Janeiro da belle époque. $2^{\mathrm{a}}$ Ed. Campinas, SP: Editora da UNICAMP, 2001.

DAMATTA, Roberto. Carnavais, malandros e heróis: para uma sociologia do dilema brasileiro. Rio de Janeiro: Zahar Editores S.A., 1983.

ESTEVES, Martha de Abreu. Meninas perdidas: os populares e o cotidiano do amor no Rio de Janeiro da Belle Époque. Rio de Janeiro: Paz e Terra, 1989.

FRÚGOLI JR., Heitor. Sociabilidade urbana. Rio de Janeiro: Jorge Zahar Ed., 2007.

GERTZ, René E. O Estado Novo no Rio Grande do Sul. Passo Fundo: Ed. Universidade de Passo Fundo, 2005.

JARDIM, Denise Fagundes. De bar em bar: identidade masculina e auto-segregação entre homens de classes populares. 1991. Dissertação (Mestrado em Antropologia Social) - Universidade Federal do Rio Grande do Sul, Instituto de Filosofia e Ciências Humanas, Programa de Pós-graduação em Antropologia, Porto Alegre, 1991.

LONER, Beatriz; GILL, Lorena; MAGALHÃES, Mario (Org.). Dicionário de História de Pelotas. Pelotas: Ed. UFPel, 2010.

MAGAlHÃES, Mario Osorio. História do Rio Grande do Sul (1626-1930). Pelotas: Armazém Literário, 2002.

MAGNANI, José Guilherme Cantor. Festa no pedaço: cultura popular e lazer na cidade. São Paulo: Brasiliense, 1984.

MATOS, Maria Izilda S. Nas fronteiras da história: a cidade iluminada. IN: NODARI, Eunice et al. (Org.). Simpósio Nacional da Associação Nacional de História (20: 1999: Florianópolis) História: fronteiras / Associação Nacional de História. São Paulo: Humanitas / FFLCH / USP: ANPUH, 1999.

MATOS, Maria Izilda S. de. Meu lar é o botequim: alcoolismo e masculinidade. $2^{\mathrm{a}}$ ed. São Paulo: Companhia Editora Nacional, 2001.

MONSMA, Karl. Conflito simbólico e violência interétnica: europeus e negros no oeste paulista, 1888-1914. História em Revista, v. 10, p. 95-115, dez. 2004.

NOVAES, José. Um episódio de produção de subjetividade no Brasil de 1930: malandragem e Estado Novo. Psicologia em Estudo, Maringá, v. 6, n. 1, p. 39-44, jan./jun. 2001.

PETERSEN, Áurea; PEDROSO, Elizabeth. Movimentos sociais urbanos (1930-1985). In: GERTZ, René. República: da revolução de 1930 à Ditadura Militar (1930-1985). Passo Fundo: Méritos, 2007.

REMEDI, José. Palavras de honra: um estudo acerca da honorabilidade na sociedade Sul-rio-grandense do século XIX, a partir dos romances de Caldre e Fião. 2011. Tese (Doutorado em História) - Universidade do Vale do Rio dos Sinos, Programa de PósGraduação em História, São Leopoldo, 2011. 
RÜDIGER, Francisco. Cotidiano, mídia e indústria cultural: modernidade e tradicionalismo, dos anos 1930 à atualidade. In: GERTZ, René. República: da revolução de 1930 à Ditadura Militar (1930-1985). Passo Fundo: Méritos, 2007.

SIMMEL, Georg. Questões fundamentais da sociologia: indivíduo e sociedade. Rio de Janeiro: Zahar, 2006.

SOARES, Luiz Carlos. Por uma genealogia da noite na cultura ocidental. In: NODARI, Eunice, et al. (Org.). Simpósio Nacional da Associação Nacional de História (20: 1999: Florianópolis) História: fronteiras / Associação Nacional de História. São Paulo: Humanitas / FFLCH / USP: ANPUH, 1999.

SOARES, Paulo Roberto Rodrigues. Do rural ao urbano: demografia, migrações e urbanização (1930-1985). In: GERTZ, René. República: da revolução de 1930 à Ditadura Militar (1930-1985). Passo Fundo: Méritos, 2007.

VIEIRA, Sidney Gonçalves. A fragmentação social do espaço urbano: uma análise da (re)produção do espaço urbano em Pelotas, RS. 1997. Dissertação (Mestrado em Planejamento Urbano e Regional) - Universidade Federal do Rio Grande do Sul, Faculdade de Arquitetura e Urbanismo, Porto Alegre, 1997. 